\title{
FIXED DRUG ERUPTION- BANE OF A BOON
}

Shashi Kiran M, Pallavi Nanaiah K, Manjunath M, Naveen B. S., Vidya S., Anil Kumar Shukla

1. Senior Lecturer. Department of Oral Medicine, Diagnosis and Radiology Dayananda Sagar College of Dental Sciences, Bangalore.

2. Senior Lecturer. Department of Periodontics, Dayananda Sagar College of Dental Sciences, Bangalore.

3. Professor \& Head. Department of Oral Medicine \& Radiology, VS Dental College \& Hospital, Bangalore.

4. Private Practitioner, Department of Oral \& Maxillofacial Surgery.

5. Private Practitioner.

6. Professor. Department of Radiodiagnosis, Kempegowda Institute of Medical Sciences, Bangalore.

\section{CORRESPONDING AUTHOR:}

Dr. Shashi Kiran M.

$604,1^{\text {st }}$ B Main Road,

Domlur Layout, Bangalore - 560071.

E-mail: drshashikiranm@yahoo.com

Medication forms one of the first basis of healing. But sometimes, like a double edged sword, it can do more harm than good. The pill that is used to cure an ailment may be the cause of misery itself. Drug reactions are a significant cause of morbidity and mortality in the world today. Clinicians are the dispensers of prescriptions for ailments and also the one to whom the patient presents with lesions to. Some of the lesions that the patient may present with are drug associated. One such lesion which a clinician should be aware of to diagnose and treat is fixed drug eruption (FDE).

FDE was first described by Bourns in 1889 and five years later, Brocq termed it "eruption erythemato pigmentee fixee". ${ }^{1}$ FDE is characterized by a single or multiple skin lesions that occur at the same site each time a drug is administered. The fixed localization of FDE on repeated administration of the same drug is a diagnostic hallmark. The cardinal morphologic feature is pigmentation that varies from dusky slate to brownish black. The genital and oral mucous membrane are involved in approximately $50 \%$ of the cases. The number and size of the lesions may increase after each exposure. Lesions are usually round or oval and well circumscribed. Edema and erythema are seen within 30 minutes to 16 hours after exposure. Lesions are usually seen more commonly in the extremities, genital and perianal areas, lesions on the mucous membrane also occur. ${ }^{2}$ Cutaneous lesions of fixed drug eruption start as a solitary erythematous macule that subsequently evolves into an edematous plaque. The eruption may start as a morbilliform, scarlatiniform or multiforme lesion. Less common types of fixed eruptions are the urticarial, nodular and the eczematous (erythematous scaly, follicular, maculopapular and vesiculopapular) types. ${ }^{3}$ Various types including atypical varieties of FDE have been described in various studies. 4,5 The glans penis of the male genitalia was the most commonly involved site (58.0\%), followed by the extremities $(39.0 \%)$, the trunk $(20.3 \%)$, and the lips (6.3\%). Generalized reactions involving the whole body are rare but are known to occur. ${ }^{6}$ Marya $\mathrm{C} \mathrm{M}$ et. al. reported a case of FDE on the hard palate due to ornidazole. ${ }^{7}$ Herpes simplex virus (HSV) is frequently reactivated in these areas of healthy individuals. ${ }^{8}$

Some of the drugs causing FDE include Trimethoprim-Sulphamethoxazole, Fursemide, Tetracycline, Diclofenac Sodium, Ciprofloxacin, Ibuprofen, Metronidazole, Norfloxacin, Aspirin 6 , naproxen sodium, dipyrone, dimenhydrinate, paracetamol ${ }^{9}$, Fluconazole ${ }^{10}$, Paracetamol ${ }^{11}$, Citrizine $^{12}$, Ornidazole ${ }^{7}$ and several other drugs and possibly, any other drug could be an 
implicating agent, making it an important adverse drug reaction that the clinician must be aware of, to treat and more importantly, avoid.

The diagnosis of FDE is primarily based on the patient's history and clinical presentation. The tests carried out to confirm a diagnosis of FDE include biopsy, Patch test, Intradermal provocation test and Intraoral provocation test.

Even though rechallenge test is the gold standard for FDE, patch test constitutes a valuable and safe tool in the determination of the offending drug of FDE. Some allergens may demonstrate a lack of reactivity which is a limitation of the test. ${ }^{13}$

In a study conducted by Mahboob A et.al. it was suggested that positive intradermal provocation test may be indicative of the incriminating drug causing FDE. 14

The oral provocation test is the classic gold standard to find the incriminating drug of FDE. Method of oral provocation test :- Written informed consent of the patient is obtained. The patients are asked not to take any susceptible drugs, antihistamines or immunosuppressives and to avoid using topical or systemic corticosteroids for atleast four weeks before and during the provocation test. Four weeks after clearance of the lesion, an oral challenge with graded doses of the suspected drug is performed starting with $1 / 8^{\text {th }}$ of a single dose. Doses are escalated at 24 hours interval to $1 / 4^{\text {th }}$, one half and one full dose if necessary. The test is considered positive if the previously involved FDE sites are reactivated with pronounced violaceous erythema with or without induration, itching or burning. If no reactivation occurs with that drug, the next suspected drug is tested only after complete remission of the first reaction. ${ }^{9}$

Although the lymphocyte transformation test (LTT) is a reliable method to identify the incriminating drug in many types of drug eruptions such as maculopapular eruptions, acute generalized exanthematous pustulosis, and drug induced hypersensitivity syndrome, positive LTT reactions are rarely obtained in patients with FDE. Nevertheless, a positive LTT reaction may be obtained in cases of generalized variant of FDE indistinguishable from Toxic Epidermal Necrolysis. In summary, oral challenge remains the most reliable method for establishing the causative drug in FDE. ${ }^{8}$

The histopathology in typical FDE is lichenoid reaction. The accompanying inflammatory cell infiltrate is a superficial and deep perivascular infiltrate. There are also neutrophils and melanophages, indicative of repeat injury at the dermoepidermal junction. However, occasionally, early lesions may show epidermal spongiosis, dermal edema, neutrophilic microabscesses, and dermal eosinophils. ${ }^{15}$

The current concept of the underlying mechanisms of FDE focuses on persistent dermal or intra-epidermal CD8+ T lymphocytes. These cells are characterized by the surface pattern of effector-type or effector-memory T cells (expression of CD45RA, CD11a, CD11b, CLA, $\alpha E \beta 7$ and absence of CD27, CD28, CD56, CD62L). Further, these T cells express the early activation marker CD69 even before challenge, and thus seem to persist in a state of activation. After challenge, these cells undergo phenotypic conversion from CD45RA+ to CD45RO+ memory-type $\mathrm{T}$ cells and produce large amounts of cytokines, particularly IFN- $\gamma$. Along with their cytolytic activity, this induces apoptosis of keratinocytes and the clinical picture of erythema, eczema like lesions or even blistering. ${ }^{16}$ Intraepidermal CD8+ T cells with an effector-memory phenotype resident in fixed drug eruption lesions have a major part to play in the development of localized tissue damage. Activation of these CD8+ T cells is enough to trigger the lesion, but not sufficient to cause large scale tissue damage observed in the fully evolved lesions; in addition, recruitment of CD4+ and CD8+ T cells to a specific tissue target site also contributes to the late stage of lesion 
development. The influx of regulatory $\mathrm{T}$ cells into the epidermis observed in fully evolved lesions would serve the purpose of limiting harmful immune reactions. Consistent with this, positive patch test reactions are only observed at the site of previous lesions harbouring significant numbers of intraepidermal CD8+ T cells. Intraepidermal CD8+ T cells may represent dual-edged sword of the skin immune system with protective and destructive capacity. ${ }^{8}$

Management of FDE: Withdrawal of the offending drug is the most important aspect of management of FDE, hence the importance of ascertaining the causative agent. Further management is based on the severity of the reaction. For mild cases, withdrawal of the drug followed by application of topical corticosteroid along with systemic antihistamines should suffice although FDE has been reported as an adverse reaction to cetrizine and levocetirizine itself. ${ }^{12}$ More severe cases are managed as would be cases of severe allergic reactions including intensive supportive therapy, maintenance of fluid and electrolyte balance, systemic corticosteroids and/or antihistamines. Antibiotics may be required to control secondary infection. ${ }^{17}$ In some patients, despite the continued administration of the causative drug, the pigmented lesions eventually disappear; such patients would be spontaneously desensitized to the causative drug. Kelso and Keating ${ }^{18}$ have reported successful desensitization for treatment of FDE to allopurinol; interestingly, desensitization to the causative drug in FDE has exclusively been reported to occur with allopurinol. 19-21

With the growing incidence of drug use and abuse, often clinicians may be faced with the task of confronting and treating drug related lesions. Fixed drug eruption is one such entity which when armed with a thorough history and clinical examination, can easily be diagnosed and future incidences of eruption avoided. Documentation of newer offending drugs and a thorough history of previous sensitization would enable the clinician to be prepared to anticipate any adverse reaction and in keeping with Hippocrates' principle of first doing no harm, would enable the clinician to avoid such adversities.

\section{REFERENCES:}

1. Brocq L. Éruption érythemato-pigmentée fixe due al'antipyrine. Ann Dermatol Vénéréol 1894; 5: 308-313.

2. Tavallaee M, Rad M M. Fixed drug eruption resulting from fluconazole use: a case report. J Med Case Rep 2009, 3:7368

3. Sehgal V M, Gangwani O P. Fixed Drug Eruption Current Concepts. Int J Dermatol March 1987, 26(2), 67-74

4. Stubb S. Blood leukocytes with special reference to basophils and eosinophils, during provocation tests in fixed eruption and drug exanthem. Acta Derm Venereol. 1976;56(Suppl 76): 1-47.

5. Sehgal VN. Causes of fixed drug eruptions. Dermatologica. 1974;148:120-123.

6. Fayez R, Obaidat N, Al-Qa'qaa' A, Al-Rawashdeh B, Ma'aita M, Al-Azab N. Drugs Causing Fixed Drug Eruption: A Clinical Study. Journal of the Royal Medical Services. 2011; September 18(3), 16-20

7. Marya C M, Sharma G, Parashar V P, Dahiya V. Mucosal fixed drug eruption in a patient treated with ornidazole. J Dermatol Case Rep. 2012; 6(1): 21-24

8. Shiohara T. Fixed drug eruption: pathogenesis and diagnostic tests. Curr Opin Allergy Clin Immunol 9:316-321

9. Bayazit E O, Bayazit H, Ozarmagan G. Drug related clinical pattern in fixed drug eruption. Eur J Dermatol. 2000; June, 10(4): 288-91 
10. Beecker J, Colantonio S. Fixed drug eruption due to fluconazole. CMAJ,2012, April 3, 184(6), 675

11. Nino M, Francia M G, Costa C, Scalvenzi M. Bullous Fixed Drug Eruption Induced by Paracetamol: Report of a Pediatric Case. Case Rep Dermatol 2009;1:56-59

12. Cravo M, Goncalo M, and Figueiredo A. Fixed drug eruption to cetirizine with positive lesional patch tests to the three piperazine derivatives. Int J Dermatol 2007, 46, 760-762

13. Andrade P, Brinca A and Goncalo M. Patch testing in fixed drug eruptions-a 20-year review Contact Dermatitis, 65, 195-201

14. Mahboob A, Haroon T S, Iqba Zl, Saleemi M A and As Muni A. Fixed Drug Eruption and Intradermal Provocation Tests. J Coll Physicians Surg Pak 2008, Vol. 18 (12): 736-739

15. Olasode 0 A. The many faces of fixed drug eruptions. Dermatologia Kliniczna 2011, 13 (1): $5-8$

16. Mizukawa Y, Yamazaki Y, Teraki Y, Hayakawa J, Hayakawa K, Nuriya H, et al. Direct evidence for interferon-gamma production by effector-memory-type intraepidermal $\mathrm{T}$ cells residing at an effector site of immunopathology in fixed drug eruption. Am J Pathol 2002; 161: 1337-1347.

17. Griffiths WA, Judge MR, Leigh IM. Drug reactions. In: Champion RH, Burton JL, Burns DA, Breathnach SM. Rook/Wilkinson/Ebling Textbook of dermatology, 6th edition, Blackwell Science Ltd, United Kingdom, 1998; p 3349-3517.

18. Kelso JM, Keating RM. Successful desensitization for treatment of a fixeddrug eruption to allopurinol. J Allergy Clin Immunol 1996; 97:1171-1172.

19. Umpierrez A, Cuesta-Herranz J, De Las Heras M, et al. Successful desensitization of a fixed drug eruption caused by allopurinol. J Allergy Clin Immunol 1998; 101:286-287.

20. Fam AG, Dunne SM, Iazzetta J, Paton TW. Efficacy and safety of desensitization to allopurinol following cutaneous reactions. Arthritis Rheum 2001; 44:231-238.

21. Teraki Y, Shiohara T. Successful desensitization to fixed drug eruption: the presence of CD25p CD4p T cells in the epidermis of fixed drug eruption lesions may be involved in the induction of desensitization. Dermatology 2004; 209:29-32. 